\title{
Key considerations before integrating modular construction: adaptation to the traditional French construction processes
}

\author{
Zakaria DAKHLI ${ }^{1}$, Zoubeir LAFHAJ ${ }^{2,4}$, Marc BERNARD ${ }^{3}$ \\ ${ }^{1}$ Ph.D candidate in Civil Engineering, Ecole Centrale de Lille \\ ${ }^{2}$ Professor in Civil Engineering, Ecole Centrale de Lille \\ ${ }^{3}$ Project Manager, Rabot Dutilleul, France \\ ${ }^{4}$ Corresponding author's e-mail: zoubeir.lafhaj@ec-lille.fr
}

\begin{abstract}
Industries around the world are improving continuously. They are converted into more efficient, dynamic and productive forms and construction is no exception to this principle. Indeed, this sector had started to get organized during the last decades. Modular design was introduced as an industrialization mean. However, few companies benefit from this concept in order to offer competitive prices and sustainable buildings. This paper, based on two case studies, presents key considerations for a successful implementation of modular design into an existing traditional construction business. Investigations were conducted to analyze the potential synergy and complementarity between modularization and the traditional French construction. The results show that modularization is viewed as a major change in the core business. As a consequence, modularization should be accompanied with a change management process. The results also revealed that modular construction goes hand in hand with a strong focus on technical frameworks. However, during the first implementation phase, spotlights should be slightly more directed into organizational planning and managerial postures.
\end{abstract}

\section{KEYWORDS}

Modular and offsite construction, traditional construction, change management,

\section{INTRODUCTION}

Construction is known to be a stagnant industry where business is done the same way for decades. Prejudice or not? This isn't the right question: the construction industry actually faced several changes over time but not noticeable as other industries. This is mainly due to the fact that those changes are incremental as opposite of a "breakthrough innovation" change.

The construction field has experienced several critical steps in history. Over time, this sector has begun to get organized, especially in ancient Mesopotamia, about $1750 \mathrm{BC}$, with the advent of the first building regulation, under the name of "Code of Hammurabi"(André-Salvini, 2008). The Roman Empire (753 BC -. 453), thanks to its technical excellence, the massive use of concrete and brick and the introduction of machinery, also contributed to the development of the construction trade (Ampère, 1862).

The major event that follows is the Industrial Revolution, which began in Britain in the late eighteenth century and then moved to France in the early nineteenth century. The standardization of production and assembly line work are the pillars of that era. The first steps 
of standardization were initiated by the industrial way of continuous production systems. Then comes the period of post-war during which construction has progressed considerably in volume, especially in Europe, due to the destruction caused by the Second World War (Europe's Postwar Recovery, 1995). The construction industry evolved drastically because it was faced with the need to rebuild the devastated cities. As a consequence, construction starts embracing Industrialization (Simonetti, 1977).

Many attempts to industrialize the construction sector were conducted after the Second World War. The need to build housing and infrastructure led to a serious reflection on improving construction processes. However, industrialization was misled by prefabrication and standardization. Those two practices normalize the production to create the same building with the same characteristics, make the environment less attractive and destroys the authenticity of the city (Resendiz-Vazquez, 2010). In 1963-1964 in France (McCutcheon, 1992) the media and academia have greatly criticized the rigid approach of industrialization. It was called the closed prefabrication which can be represented as follows (Delrue, 1976).

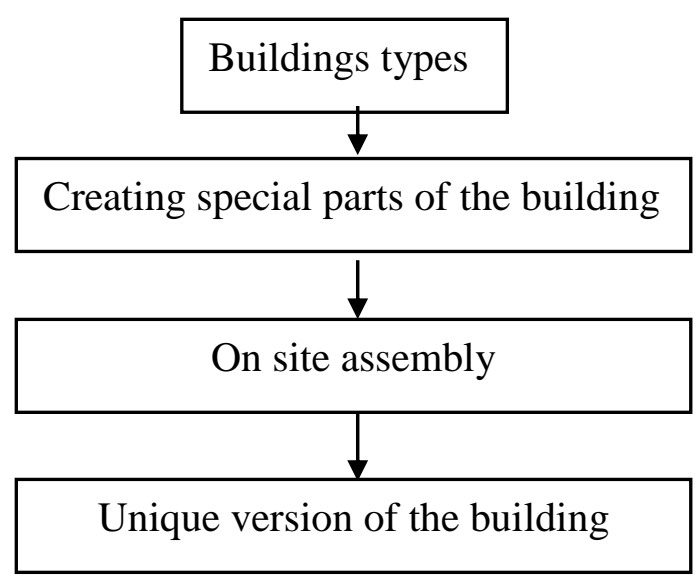

Figure 1. Principle of closed industrialization (Delrue, 1976)

The close industrialization is the production of elements or building blocks (entire room, kitchen, etc.). Thus, it considerably reduces the flexibility of the construction. This concept could not last long as a new thought was given to achieve the so-called 'open' industrialization (Delrue, 1976; Simonetti, 1977). Indeed, the change lies in the focus on small parts (components such as windows, doors ...) and not entire parts of the building.

It is true that prefabrication can be considered as a major event in improving construction processes. However, industrialization doesn't only concern prefabrication and must be viewed as a kind of revolution in the way of building : materials, processes implemented, flow and scales (Simonetti, 1977).

Azambuja M. and W. O'Brien (O'Brien, Formoso, Ruben and London, 2008, chap.1) highlighted the differences between manufacturing and construction systems based on: structure, information flow, collaboration, product demand and variability, buffering and capacity planning. The gap results in different characteristics: the manufacturing industry is based on mass production, variability in reduced supply, continuous improvement and integration of efficient logistics while construction is a limited production (a few projects per 
year) and highly fragmented (Fulford and Standing, 2014) several actors are working on the same project which make managing and precise definition of processes very subtle.

\section{Modular construction}

Modular construction could be defined as an offsite process fabrication followed by transportation and onsite assembly. The purpose is to transform the construction processes to make them as industrial as possible. Modular construction helps reduce construction time compared to traditional methods. It also guarantees a certain level of quality due to the control established in the production chain. Finally, it helps reduce project variability. However, many companies do not fully benefit from the potentials provided by modularization ( $\mathrm{Yu}, \mathrm{Al}-\mathrm{Hussein}$, Al-Jibouri and Telyas, 2013).

\section{Context of the study}

Modular construction is viewed as a new strategy in the construction industry. This is because it is considered as a new way of doing business by providing a different "solution" to the client. It is easier to start a new business model than to "recalibrate" by adapting to the advances made within one industry. Our study concerns the introduction of modular construction concepts in a construction company.

The company has been used, for decades, to deal with traditional construction methods. Its main activities concern: housing, commercials, offices and public facilities. It started to think about modular construction in 2007. However, modular construction was launched in 2009 as a subsidiary.

Currently, strategic choices are directed towards investing in modular construction and enabling it as a future growth pillar. Indeed, project management team has increased progressively during the last 3 years (figure 2) and the budget invested in developing modular solutions followed as well.

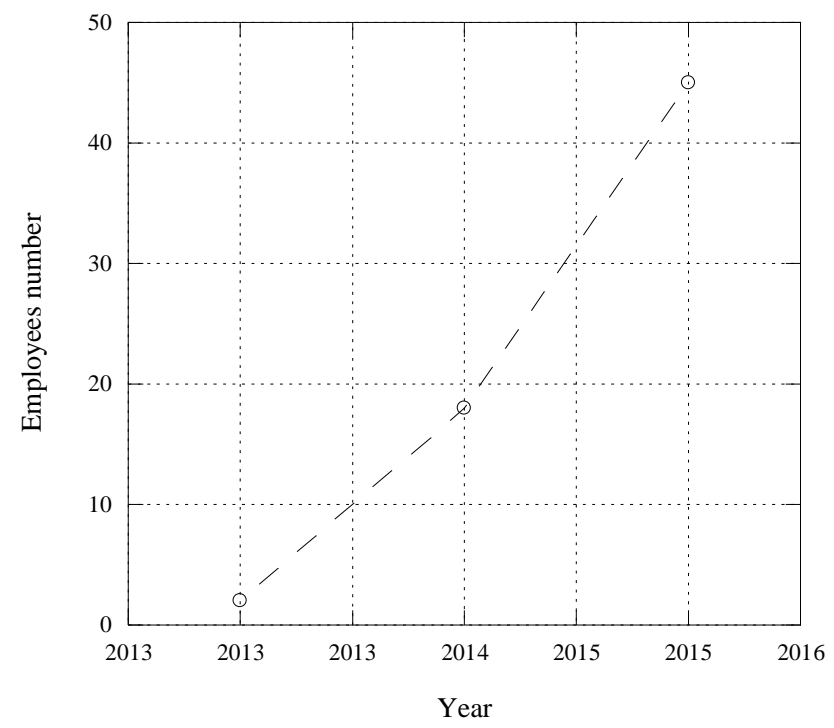

Figure 2. Number of employees within the modular construction subsidiary 
The core business of the modular construction subsidiary is modular housing solutions. 15 trades out of 18 are integrated in the factory during the fabrication process.

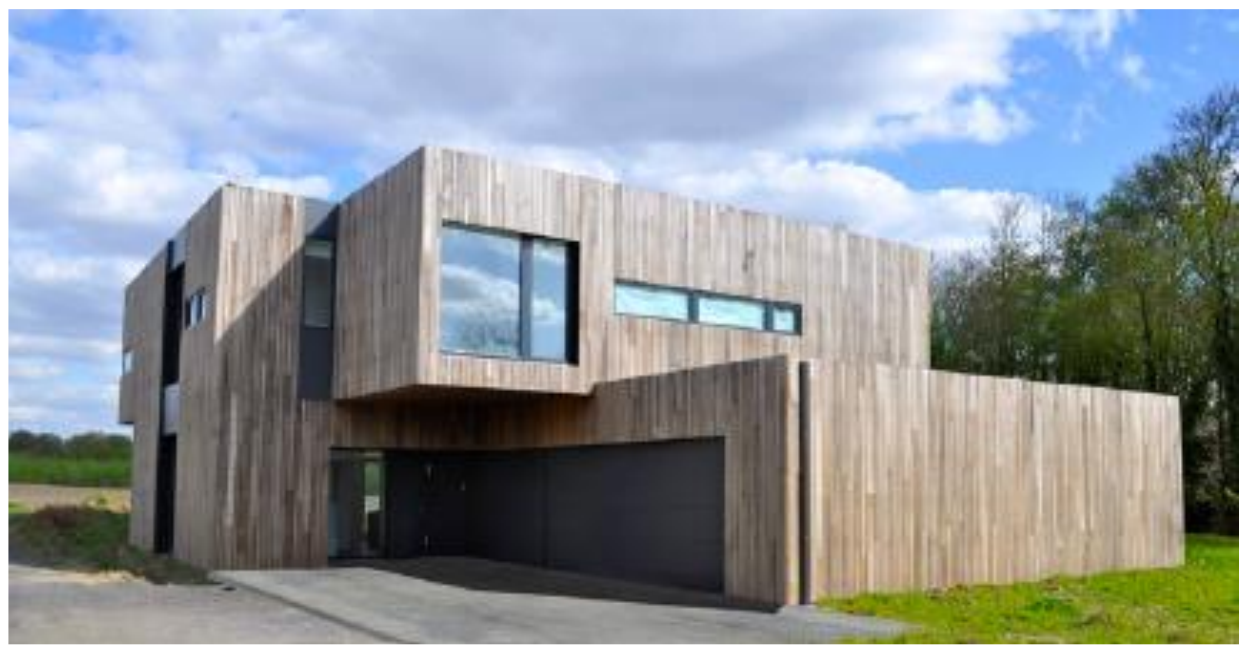

Figure 3. Modular house first prototype

The first house prototype was a $300 \mathrm{~m}^{2}$ built. It took one day to fabricate one housing module, two days for onsite assembly and one week for finishing.

Technical frameworks were established and the next step was to launch modular construction projects within the company. This study deals with the "implementation phase" and the challenges faced to introduce modular construction within an existing traditional construction processes of a construction company.

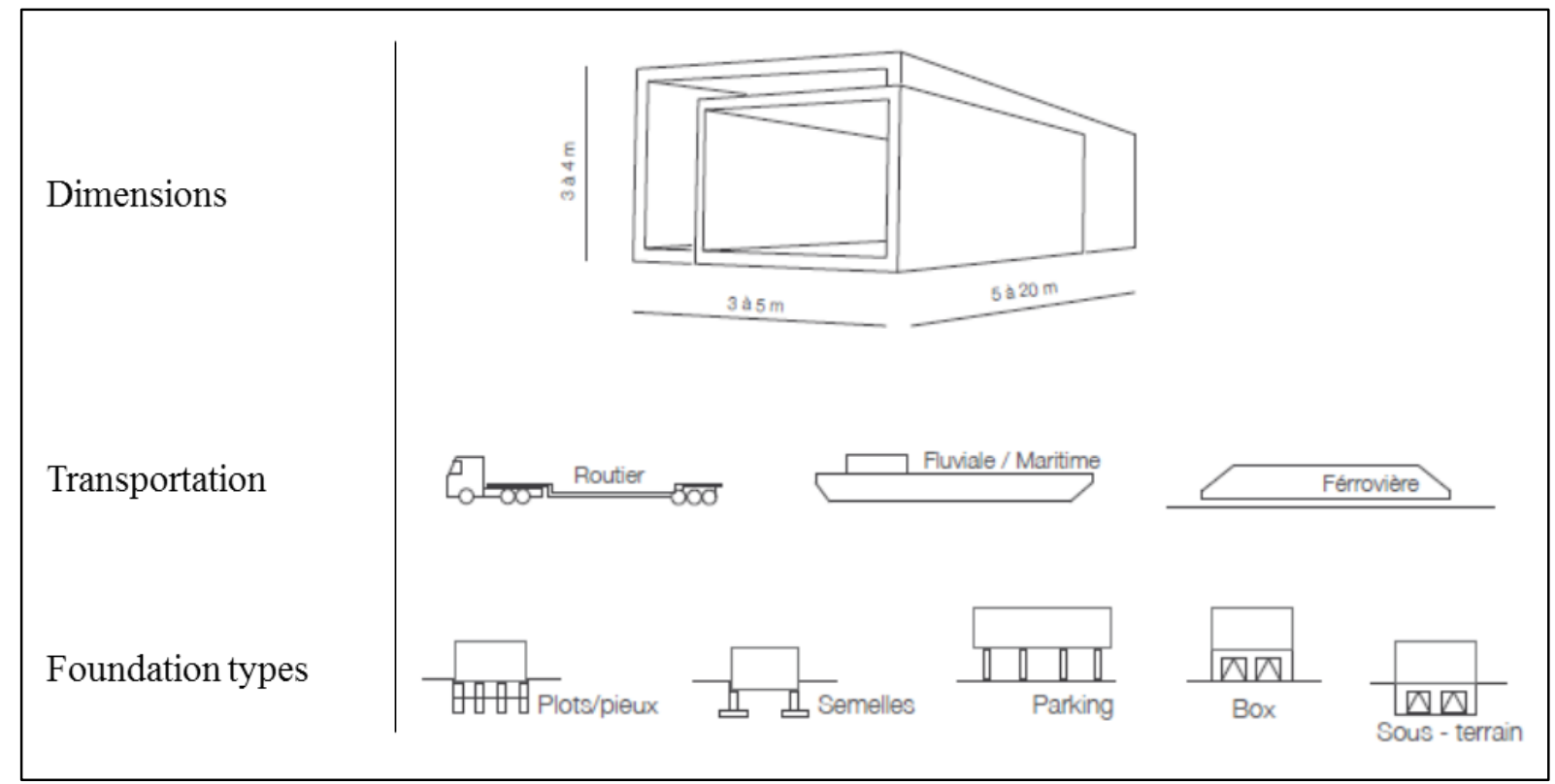

Figure 4. Specifications regarding: dimensions / transportation / foundations onsite 


\section{RESEARCH METHODOLOGY}

The research is based on the case study methodology according to (Yin, 2013). Two projects, done by the construction company in collaboration with the modular construction subsidiary, are investigated in this study. Data were also collected from different sources:

- Semi-structured interviews with collaborators and executives: the researcher was introduced within the company for a long period of time (one year) in order to draw a vision of what collaborators think might be suitable to achieve regarding modular construction.

- Presentations in committee meetings.

- Archives and documents.

\section{RESULTS AND DISCUSSIONS}

Two projects, where modular construction was integrated, are exposed. The first case concerns a Design/Build operation whereas the second is in a Design/Bid/Build configuration. Afterwards, analysis and conclusions are drawn based on the two case studies.

\section{First Case study}

200 student accommodations in a five floor building. A Design/ Build operation led by the construction company with a total cost of $8070 \mathrm{~K} €$. This procurement system is characterized by the signature of one single contract for the client. As a consequence, the owner deals with only one entity for the design and the construction execution.

The choice of integrating modularization in the project was confirmed in the beginning and shared with all the stakeholders (client, architect, engineering firms).

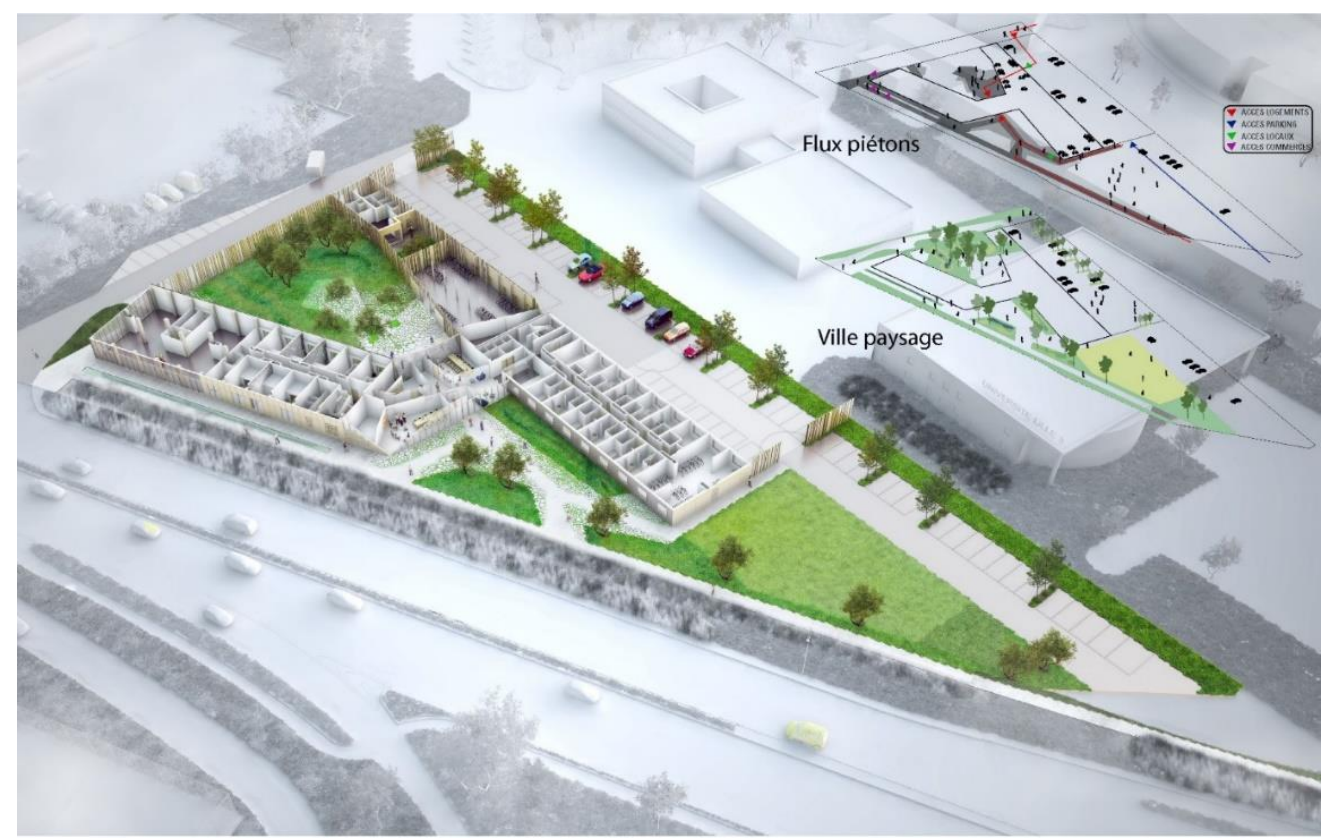

Figure 5. Project overview 
Services provided by the construction company (traditional construction) and its subsidiary (modularization) were first identified and priced (table 1).

Table 1. Services provided by the construction company and its modular subsidiary in a $\mathrm{D} / \mathrm{B} / \mathrm{B}$ configuration

\begin{tabular}{|c|c|}
\hline Construction company & Modular subsidiary \\
\hline Foundations & \multirow{6}{*}{$\begin{array}{l}\text { Housing modules all engineering works } \\
\text { included }\end{array}$} \\
\hline Stairs and escalator installation & \\
\hline Central building & \\
\hline $\begin{array}{l}\text { Ground floor of one building (for } \\
\text { commerce) }\end{array}$ & \\
\hline $\begin{array}{l}\text { Ducts and conveyance systems and their } \\
\text { finishing. }\end{array}$ & \\
\hline Concrete facade cladding & \\
\hline
\end{tabular}

Modular Construction Company proposed a package composed of two houses and the common alley (figure 6) in order to enable standardization using modularization

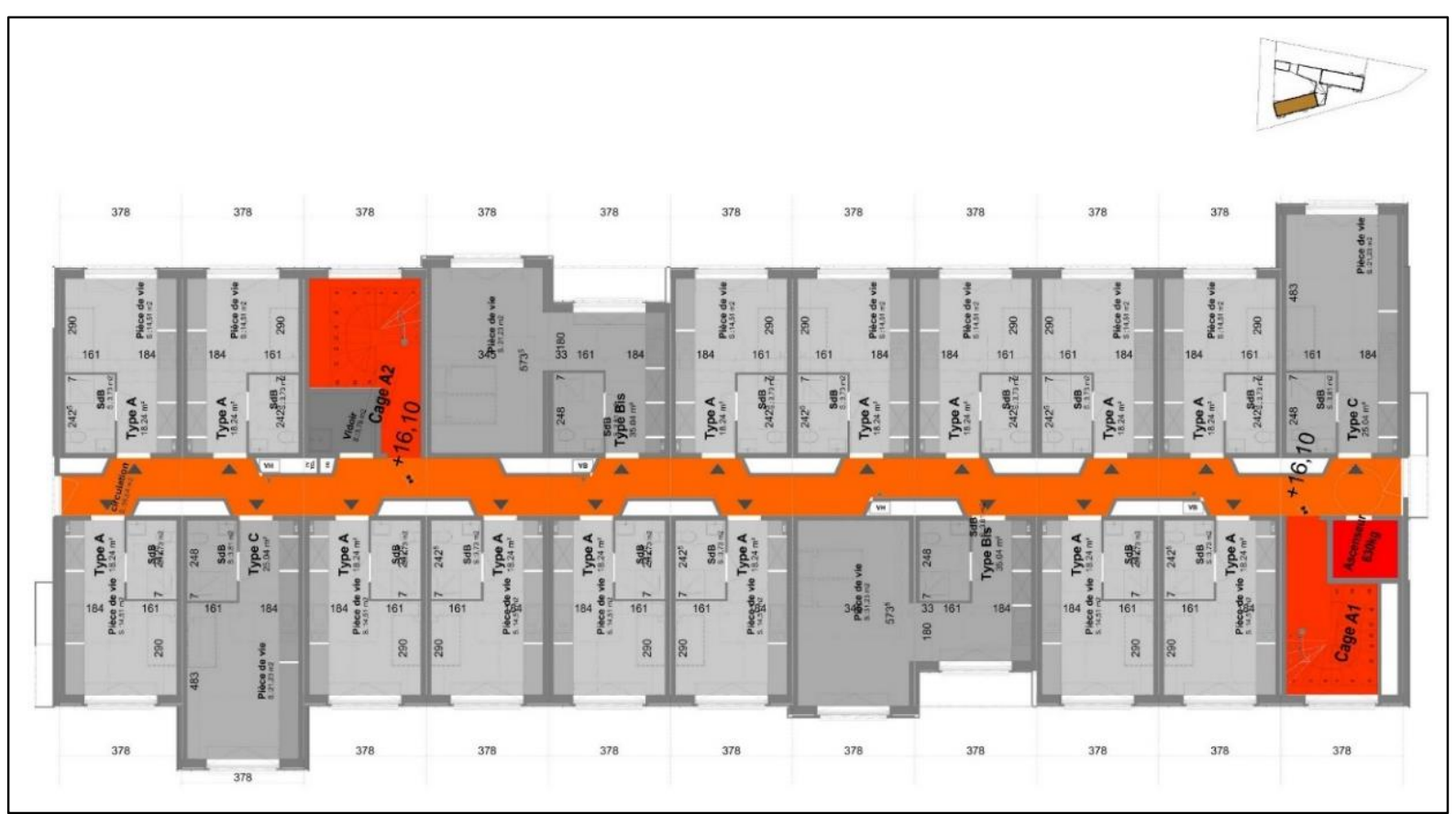

Figure 6. 2-types "A" modules with the common alley as a package proposal in order to maximize standardized work

The main effect was translated into "time reduction". Figure 7 describes project phases and the predicted and actual date delivery. 


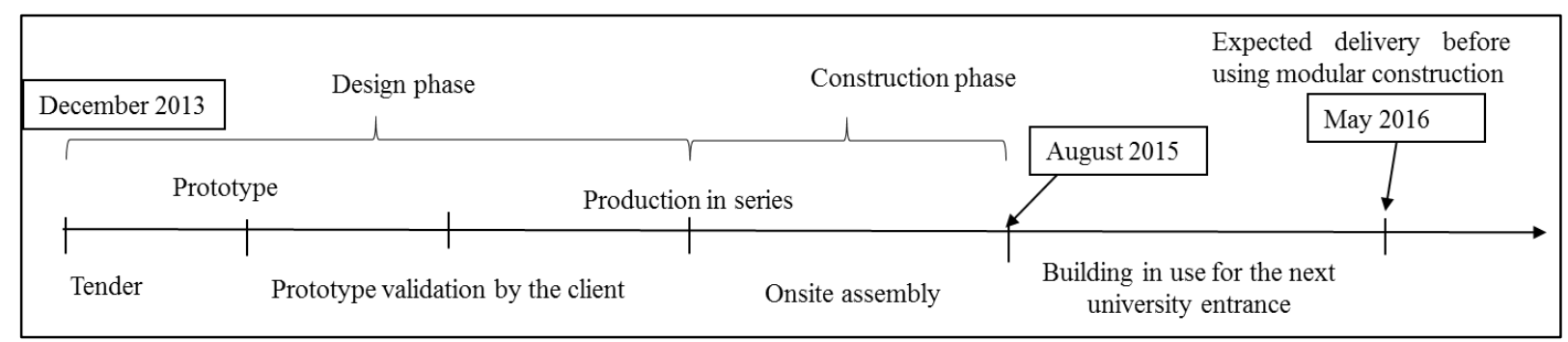

Figure 7. Project timeframe

\section{Second case study}

16 wooden houses. The project was undertaken in a Design/Bid/ Build procurement system with a total project cost of $1750 \mathrm{~K} €$. The Design / Bid / Build procurement system is the traditional delivery method characterized by a sequential process that starts with project design established by an appointed designer (the architect). Once the design is finished, the contractor is selected using some criteria (price, technical feasibility, sustainability). However, the main criteria of selection usually is price. This phase is called the bidding phase. The selected contractor can begin the construction with a completed design and a fixed schedule.

The first step of tender is to select the services provided by the modular subsidiary (table 2).

Table 2. Services provided by the construction company and its modular subsidiary in a D/B configuration

\begin{tabular}{ll}
\hline Construction company & Modular subsidiary \\
\hline Slab garages & Foundations \\
\hline Wooden frame & Housing modules \\
\hline Facade cladding & \\
\hline
\end{tabular}

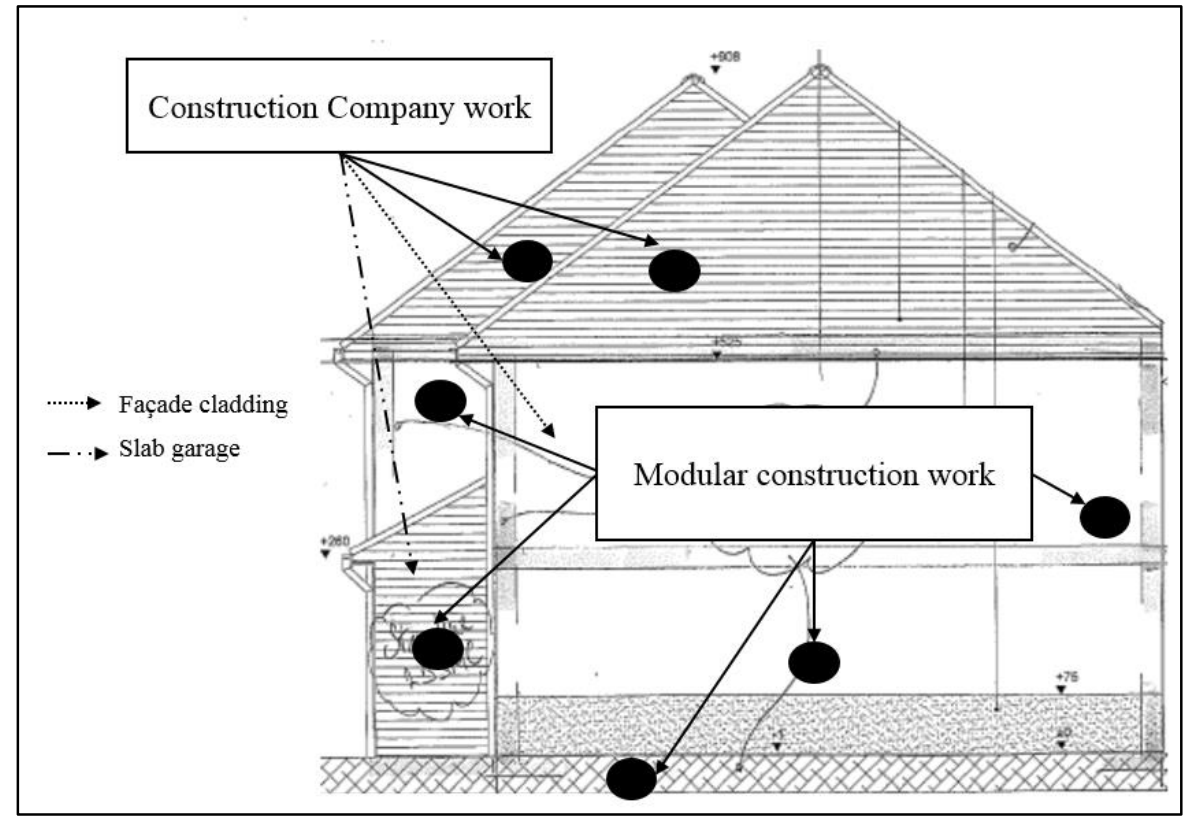

Figure 8. Work division according to: traditional / modular construction 


\section{Technical framework analysis}

Procurement systems adaptation. The consequence of going for a Design/Bid/Buid procurement system (case study 2) is that the project design is already fixed during tender. Thus, introducing modular construction is more delicate compared to the Design/Build procurement system (case study 1) where the design is modular-oriented in the first place.

As a consequence, the full benefit of modularization was met in a Design/Bid/Build configuration where time schedule was reduced with a positive impact for all the stakeholders. The early decision taken of going modular prevented from many problems in the construction phase.

Regulation adjustment. Usually, technical frameworks of modules are established in order to "sell" the modular products to construction companies in a co-contractor configuration or directly to the client in a contractor configuration.

The major challenge noticed related to technical frameworks of modules is their adaptability regarding regulations. Indeed, many regulations exist that concerns acoustic, seismic resistance, thermal properties and energy efficiency.

Regulations change from one type of building to another. For instance, industrial plants need more attention regarding fire resistance. Another important point is that regulations sometimes change from one region to another. For instance, housing energy efficiency is more delicate to meet in North than south due to the cold weather. Finally, modular construction companies will find challenges to internationalize because of regulations matters.

Cost adjustment. Before starting the two case studies, modular work price was estimated at $1.000 € / \mathrm{m}^{2}$ based on the prototype constructed beforehand.

Table 3. Project cost ratio for the two case studies

\begin{tabular}{lll}
\hline & Case 1 & Case 2 \\
\hline Habitable surface area $(\mathbf{m} 2)$ & 4143 & 1258 \\
\hline Annex areas and utilities $(\mathbf{m} 2)$ & $\begin{array}{l}1633 \text { (circulation, } \\
\text { commerce, building hall...) }\end{array}$ & 259 (for garages) \\
\hline Total $(\mathbf{m} 2)$ & 5776 & 1517 \\
\hline Project cost $(\boldsymbol{\epsilon})$ & 8070 & $1750 \mathrm{~K}$ \\
\hline Total Ratio work $\left(\mathbf{\epsilon} / \mathbf{m}^{\mathbf{2}}\right)$ & 1397 & 1153 \\
\hline
\end{tabular}

The obtained ratio reveals that project cost is exceeded in the two case studies. In the first case, variability is greater. This is mainly due to the Annex areas that are part of the project but not taken as a habitable area. If annex areas surface increases, variability increases as well.

This is mainly due to the limit of services established in the beginning of the project. Annex areas are achieved using traditional construction methods which, increases project cost. Thus the more modularization is used, the less project variability increases. 
For instance, in the second case study where the design was already fixed (D/B/D configuration), modular construction company was selected to deliver the entire home. However, after a few weeks during the tendering process, the project manager found that the fabricated modules contain necessarily a high-floor wall to seal where project specifications oblige the use of a wooden frame. To solve this issue, the wooden frame was made using traditional construction. As a consequence, project cost in bidding increases due to variability.

Mapping modular construction project enablers. Modular construction adds value to the project, for both the client and the contractor. Indeed, time reduction, planning and cost control are the main benefits from modularization. To fully benefit from its impact, the construction company should identify the possible services provided by modular construction subsidiary. Those services could be identified according to the different roles played in a particular project (contractor, co-contractor or subcontractor). The next step is then to analyze the company's archive in order to identify the repeated elements (stairs, etc.):

- With a high Cost.

- Used in different project types (housing, commercials...)

With the purpose of integrating those elements as a modular construction service.

\section{Organizational framework analysis}

In the two case studies, modular construction is seen as a new way of doing business. Thus, it is considered as a shift in the company's core business. As a consequence, a change management process that goes hand in hand with modular construction implementation is required. Indeed, collaborators need to find the benefits from it in order to systematically think of implementation in their future project. The two cases reveal that to successfully integrate modular construction, the first selected project should be adequate because collaborators needs proofs and encouragement. The study revealed that $\mathrm{D} / \mathrm{B} / \mathrm{B}$ are the most adequate for first experiences.

Many attempts were conducted to develop a change model in construction. In their paper, (Motawa, Anumba, Lee and Peña-Mora, 2007) developed an integrated change management system that deals with the contractor-client perspective. In the case of integrating the modular construction within the existence processes, a model should be developed where "the client" is referred to as "collaborators": an intern process change.

Finally, strategic choices should be taken for a successful integration. It was the case in the construction company where executives fixed an indicator that follows modularization integration within projects.

Potential synergy of traditional construction and modularization. In the second case study, the project was assigned using a $\mathrm{D} / \mathrm{B} / \mathrm{B}$ procedure. The traditional tendering process was drawn to assess the potential synergy with modularization.

In figure 9, the traditional tendering process starts with project selection. After that, project feasibility is evaluated in order to validate the tendering process. Providers are selected afterwards based on project specifications and needs. This step takes time and a lot of communication and negotiation to come up with the "best" provider of a certain service.

The next step is to establish methods, construction and engineering packages establishment. With the purpose of meeting the targeted price (or lowering the price), design change by the 
contractor and providers is inevitable. (Bröchner and Badenfelt, 2011) investigated the changes made during the project lifecycle. Their study revealed that the early collaboration is associated with lower change frequency.

For both case studies, modular integration was before the projects start. As a result, the change made usually in the design is significantly diminished. However in the second case study, the design change occurred mainly at the beginning to set limits of services provided by modular work due to feasibility matters (modules' high-floor wall constraints). In the first case study, the ratio of services provided by the modular subsidiary was $50 \%$ and $70 \%$ in the second case study. The rest was set using traditional construction methods.

The study revealed that the synergy between traditional and modular construction in tender occurs mainly during the following processes:

- Providers' selection: reduction of time and risk taken due to a bad selection is proportional to the ratio of modules introduced within a project.

- Methods establishment: parts of the construction that need onsite work and offsite assembly.

- Engineering and construction packages: the modules used in the case study are composed of 15 out of 18 engineering packages.

Finally, in a modular construction configuration, the targeted price is well controlled from the beginning of tender. Thus, change due to cost overrun is less frequent compared to traditional construction which leads to avoiding the "study adjustment" process.

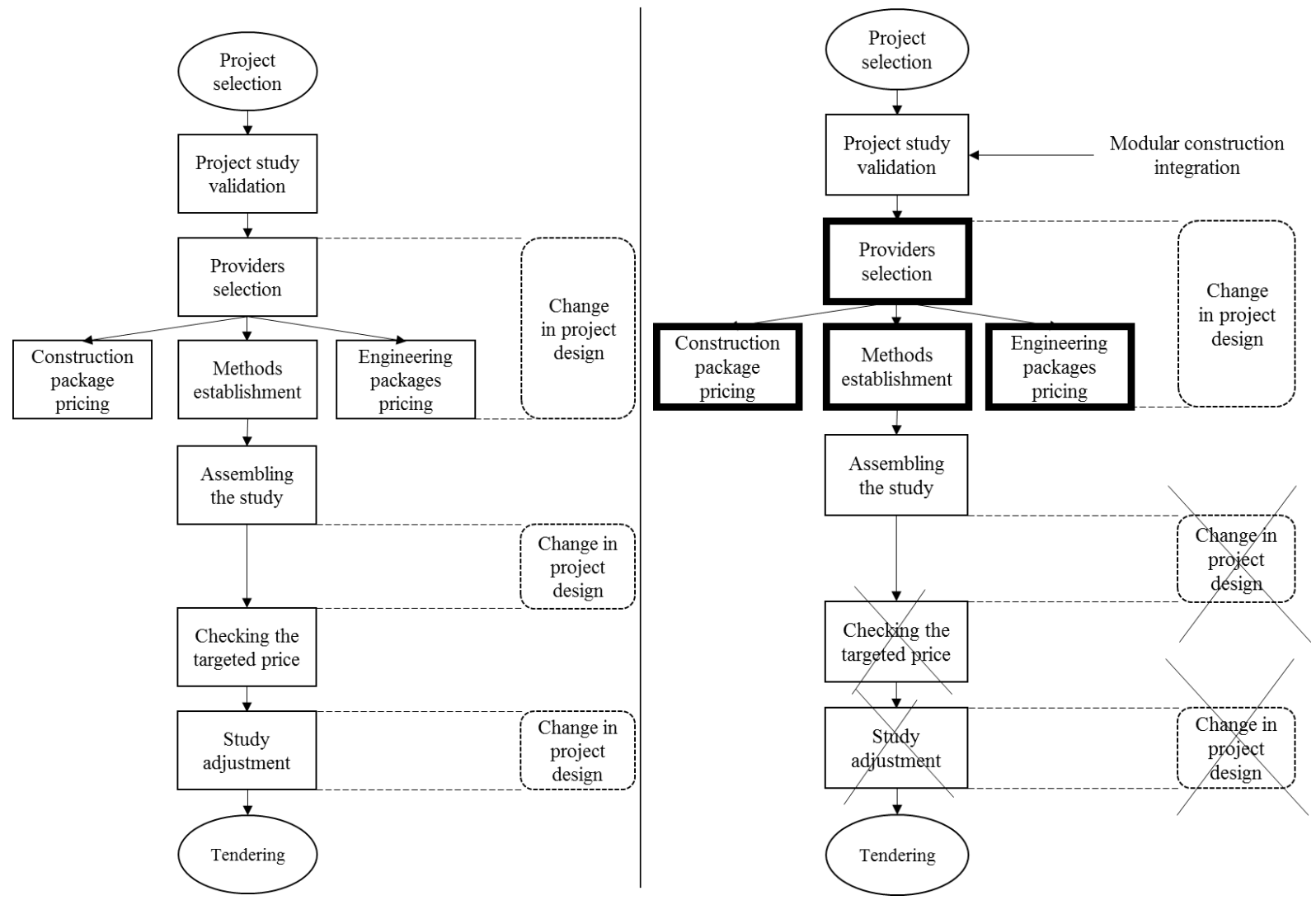

Figure 9. Traditional vs. modular integration tendering. 


\section{CONCLUSION}

The research study deals with implementation issues of modular construction within an existing traditional construction business. For that, two case studies were investigated based on two different projects. The results can be resumed as follow:

- Procurement systems play a major role as a modularization enabler.

- Services provided by modular concept should be well defined and scoped.

- From the collaborators' point of view, finding regulations mismatches with modules generates a negative perception by adding additional work on modules and thus, a reluctance of using modular design.

- Cost variability must be controlled and well established before the operation starts. If not, collaborators would probably take less risks by choosing the traditional way of doing business.

- Modular construction should be accompanied with a strong change management team that not only seeks to enhance the use of modular solutions but gives feedbacks to top management of implementation issues.

- Services provided by the modular construction subsidiary should expand and start by tackling the highest cost elements the company deals with repetitively.

- A synergy between traditional and modular construction is possible and requires a clear attention for a successful first implementation into existing processes.

Further research should focus on developing other success factors for modularization introduction into existing traditional construction processes. In addition to that, more studies should be conducted to describe services provided by modular capabilities as a function of procurement methods and projects types (housing, industrial plants, etc.)

\section{ACKNOWLEDGMENTS}

We would like to thank M. Thibaut LEROY, director of the modular construction subsidiary for his collaboration. We also would like to thank the pricing department for their valuable insights.

\section{REFERENCES}

Ampère, J.-J., 1862. L'histoire romaine à Rome. Tome 1 / par J.-J. Ampère,

André-Salvini, B.A.-S., 2008. Le Code de Hammurabi. solo. RMN.

Anon, 1995. Europe's Postwar Recovery. p.357.

Bröchner, J. and Badenfelt, U., 2011. Changes and change management in construction and IT projects. Automation in Construction, 20(7), pp.767-775. 
Delrue, J., 1976. Rationalisation de la planification et de la construction des installations des soins médicaux dans les pays en développement.

Fulford, R. and Standing, C., 2014. Construction industry productivity and the potential for collaborative practice. International Journal of Project Management, 32(2), pp.315-326.

McCutcheon, R.T., 1992. Science, Technology and the State in the Provision of Low-Income Accommodation: The Case of Industrialized House-Building, 1955-77. Social Studies of Science, 22(2), pp.353-371.

Motawa, I.A., Anumba, C.J., Lee, S. and Peña-Mora, F., 2007. An integrated system for change management in construction. Automation in Construction, 16(3), pp.368-377.

O'Brien, W.J., Formoso, C.T., Ruben, V. and London, K., 2008. Construction Supply Chain Management Handbook. p.508.

Resendiz-Vazquez, A., 2010. L'industrialisation du bâtiment: le cas de la préfabrication dans la construction scolaire en France (1951-1973).

Simonetti, J.-O., 1977. Réflexions sur l'industrialisation de la construction et la production du bâti. Norois, [online] 96(1), pp.561-572.

Yin, R.K., 2013. Case Study Research: Design and Methods. p.312.

Yu, H., Al-Hussein, M., Al-Jibouri, S. and Telyas, A., 2013. Lean Transformation in a Modular Building Company: A Case for Implementation. Journal of Management in Engineering, 29(1), pp.103-111. 